\title{
Essential role of stromal mesenchyme in kidney morphogenesis revealed by targeted disruption of Winged Helix transcription factor $B F-2$
}

\author{
Victor Hatini, ${ }^{1,2}$ Sung O. Huh, ${ }^{1}$ Doris Herzlinger, ${ }^{3}$ Vera C. Soares, ${ }^{2}$ and Eseng Lai ${ }^{1,4}$ \\ ${ }^{1}$ Cell Biology Program and Division of Endocrinology, and ${ }^{2}$ Molecular Biology Program, Sloan-Kettering Division, Cornell \\ University Graduate School of Medical Sciences, Memorial Sloan-Kettering Cancer Center, New York, New York 10021 \\ USA. ${ }^{3}$ Department of Physiology and Biophysics, Cornell University Medical College, New York, New York 10021 USA.
}

\begin{abstract}
Metanephric mesenchyme gives rise to both the epithelial cells of the nephron and the stromal cells of the mature kidney. The function of the stroma in kidney morphogenesis is poorly understood. We have generated mice with a null mutation in the Winged Helix (WH) transcription factor BF-2 to examine its function during development. BF-2 expression within the developing kidney is restricted to the stromal cell lineage.

Homozygotes die within the first $\mathbf{2 4} \mathrm{hr}$ after birth with abnormal kidneys. Mutant kidneys are small, fused longitudinally, and rotated $90^{\circ}$ ventrally. Histological examination reveals a smaller collecting system, numerous large condensations of mesenchyme, and a decrease in the number of nephrons. Using molecular markers we show that induction and condensation of the nephrogenic mesenchyme occurs normally in mutant. The disruption of $B F-2$ reduces the rate of differentiation of the condensed mesenchyme into tubular epithelium, as well as the rate of growth and branching of the ureter and collecting system. Our findings demonstrate that BF-2 and stromal cells have essential functions during kidney morphogenesis. Furthermore, they suggest that BF-2 controls the production, by the stroma, of signals or factors that are required for the normal transition of induced mesenchyme into tubular epithelium and full growth and branching of the collecting system.
\end{abstract}

[Key Words: Development; inductive interactions; metanephros; interstitium; nephron]

Received March 21, 1996; revised version accepted May 9, 1996.

Morphogenesis of all epithelial tissues during development is dependent on paracrine factors secreted by an adjacent mesenchyme (for review, see Bard 1990; Mizuno and Yasugi 1990; Birchmeier and Birchmeier 1993). In the mammary gland, gut, and lung, this mesenchyme is a stromal cell lineage that presents growth factors, extracellular matrix proteins, and cell-associated signaling molecules to a distinct epithelial progenitor population. Collectively, these stromal factors regulate epithelial differentiation and are responsible for establishing the unique differentiated properties of these organs (Wessells 1970; Cunha 1976; Hilfer et al. 1985; Haffen et al. 1987).

Like all other tubular epithelial organs, the mammalian kidney derives from two interacting mesenchymal and epithelial primordia, metanephric mesenchyme and ureteric bud, respectively (for review, see Saxen 1987; Ekblom 1992). During development, metanephric mesenchyme supports the growth and branching of the ureteric bud, which gives rise to the renal collecting system.

${ }^{4}$ Corresponding author.
In turn, the branching ureteric bud induces metanephric mesenchyme to differentiate into nephrons and renal stroma (Grobstein 1955, 1956). Thus, unlike the mesenchymes of other tubular epithelial organs, metanephric mesenchyme gives rise to both stroma and epithelia. Discrimination between these two mesenchymal cell lineages early in kidney development has yet to be achieved, in part because of the lack of early genetic markers of the stromal cell lineage (Ekblom and Weller 1991) and the inability to separate them from other mesenchymal cells early in development (Gossens and Unsworth 1972). Therefore, the role of a distinct renal stromal cell lineage in regulating kidney morphogenesis remains poorly characterized. Most models of kidney development either do not include a role for stromal cells or suggest only a supportive role (Ekblom and Weller 1991). Inductive signals promoting the growth and branching of the ureter have been attributed solely to the nephrogenic mesenchyme. Conversely, signals from the ureter are considered to be sufficient for the differentiation of the nephrons from the nephrogenic mesenchyme (Saxen 1987; Ekblom 1992). Several studies 
indicate that stroma derived from metanephric mesenchyme may mediate both ureteric bud branching and differentiation of nephron epithelia subsequent to induction (Sariola et al. 1988). However, confirmation of this hypothesis requires an experimental system with a specific defect in the stromal lineage in which kidney morphogenesis can be evaluated. Recently, a number of targeted mutations in mice have provided new insight into the molecular pathways regulating kidney morphogenesis (Kreidberg et al. 1993; Schuchardt et al. 1994; Stark et al. 1994; Dudley et al. 1995; Luo et al. 1995; Torres et al. 1995). However, none of these has shed light into the function of the stroma.

Winged Helix $(\mathrm{WH})$ proteins are a family of transcription factors that share an evolutionarily conserved DNAbinding domain. WH factors play diverse roles in pattern formation, cell proliferation, and cell fate specification (Lai et al. 1993). The role of WH genes in development was initially appreciated through analyses of mutations in Drosphila and the expression pattern of WH genes in vertebrates (Weigel et al. 1989; Lai et al. 1991). More recently, the function of $\mathrm{WH}$ genes in vertebrate development has been examined in mouse models. Targeted disruptions of the $H N F-3 \beta$ and $B F-1$ genes, as well as the spontaneous mutation of the whn gene in the nude mouse, have demonstrated the essential role of WH genes in patterning and morphogenesis in vertebrates (Ang and Rossant 1994; Nehls et al. 1994; Weinstein et al. 1994; Xuan et al. 1995). The BF-2 WH protein is a putative transcription factor identified by homology to $H N F 3-\alpha$. Within the nervous system, BF- 2 is expressed in the ventral diencephalon and temporal hemiretina. BF-2 is also expressed in several mesenchymal lineages, including a subset of cells in the developing kidney (Hatini et al. 1994).

To examine the role of $\mathrm{BF}-2$ during development we generated mice with a disruption of the $B F-2$ gene. Mice homozygous for the BF-2 null mutation develop abnormal kidneys. Defects are observed in two components of the kidney, the ureteric bud epithelium and the nephrogenic mesenchyme. The ureter and the collecting system are smaller, and the differentiation of the metanephric mesenchyme to nephrons is inhibited. We show that BF-2 is not expressed in these two components of the developing kidney but is instead restricted to a third population of cells, the stromal mesenchyme. Thus the BF-2 $(-1-\mid$ mutant mouse provides the first system to study directly the role of the stroma in kidney development. Our data demonstrate that the stroma produces factors that are essential for the differentiation of nephrogenic mesenchyme and for the growth of the ureter and the collecting system and suggest that BF-2 controls the generation of these factors.

\section{Results \\ Generation of BF-2 (-1-) mutants}

To examine BF-2 function during development, the BF-2 gene was disrupted by homologous recombination in embryonic stem (ES) cells. Mapping of the BF-2 gene showed that the major transcript is encoded in a single exon. A targeting vector was designed in which the coding region of $B F-2$ was replaced with $l a c Z$ and a $n e o^{r}$ cassette (Fig. 1A). The lacZ gene was inserted downstream of the $B F-2$ transcription initiation site as a reporter for $B F-2$ promoter activity. The vector was introduced into CI7 ES cells (Swiatek and Gridley 1993), and four clones containing the predicted mutant allele were identified by PCR and confirmed by Southern analysis at a frequency of 1 targeted colony per 200 G418-resistant colonies. One clone transmitted the BF-2 mutation through the germ line. Heterozygous mice had no obvious abnormal phenotype and were fertile. To determine the phenotype of $B F-2$ homozygous animals, mice were intercrossed and offspring were allowed to develop to term. At birth, $B F-2(-/-)$ mutant pups were initially indistinguishable from their normal littermates. However, they failed to feed, and after several hours they developed a rapid respiratory rate and accumulated air in their stomach. All $B F-2(-/-\mid$ mutant mice died within $24 \mathrm{hr}$ after birth. Genotyping of embryos and newborn animals by Southern analysis demonstrated that $B F-2$ $(-/-)$ mutants survive to term. Of 265 neonates, $24 \%$ were homozygous for the BF-2 mutation. Dissection of homozygous mice revealed major anomalies in the kidneys. Subtle abnormalities are also apparent in the retina, forebrain, and adrenal gland. This study focuses on the effects of $B F-2$ gene disruption on kidney development. Germ-line chimeras were also crossed to $129 \mathrm{~Sv} / \mathrm{J}$ females to place the mutation in an inbred background. The phenotype of the BF-2 homozygotes was identical in inbred or hybrid genetic backgrounds.

\section{$\mathrm{BF}-2(-/-)$ mutants have small kidneys}

In all $B F-2|-/-|$ mutant mice at term, the kidneys are smaller in size, fused longitudinally and rotated $90^{\circ}$ ventrally, relative to wild-type kidneys (Fig. 1C). Mutant kidneys do not ascend to their usual position and are thus separated from the adrenal glands. The ureters in homozygotes are approximately one-half the normal length, and their diameter is normal. The shorter ureter most likely accounts for the low position of the mutant kidneys in the pelvis. Other structures of the urogenital system, including the ovaries, testis, and bladder, appear normal. The adrenal glands are half of normal size. To determine when homozygous kidneys become growth retarded, kidneys were dissected and their size was compared at different stages of development (Fig. 2). At embryonic day 12.5 (E12.5), mutant and wild-type kidneys are similar in size (Fig. 4A,D, below). By E14.5, homozygous kidneys are one-half the size of wild-type kidneys. Mutant kidneys continue to grow more slowly so that at term, they are less than one-third of normal size (for details, see Materials and methods). Histological studies demonstrate that the mutant kidneys are fused only by apposition of their capsules. Examination of the kidneys during embryogenesis confirms that the two kidneys form separately and become fused later in development (Fig. 4C,G, below). 
A

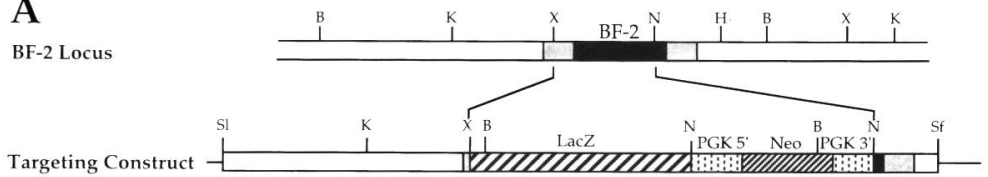

Targeted Locus

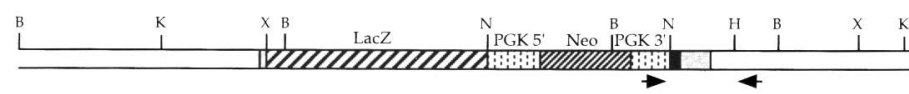

B

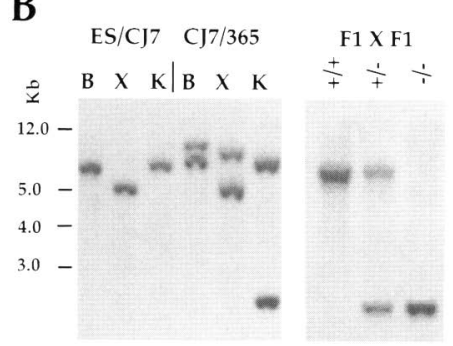

C

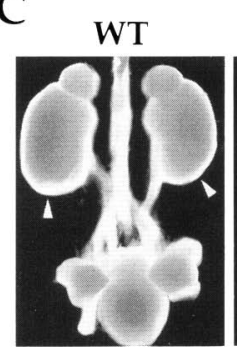

BF-2 $-/-$

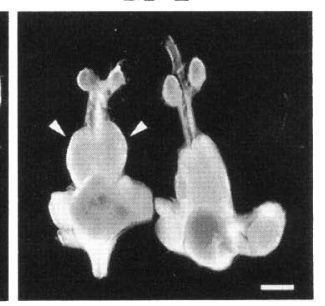

Figure 1. Targeted disruption of the $B F-2$ locus and resulting kidney phenotype. $(A)$ Schematic diagram of the $B F-2$ locus, the targeting vector, and the targeted locus. The transcribed region of $B F-2$ is contained within a $2.5-\mathrm{kb}$ region. The $B F-2$ translated region is depicted in black, and the flanking untranslated regions in gray. To generate a likely null mutation, the XbaI-NotI fragment, which contains most of the BF-2 translated region, was replaced with $1 a c Z$ and PGK-neo ${ }^{\mathrm{r}}$ cassettes. lac $Z$ was inserted downstream of the $B F-2$ transcription initiation site to provide a reporter for the activity of the BF-2 promoter. Positive ES cell clones were isolated using PCR, with primers (see arrows) flanking the $3^{\prime}$ junction of

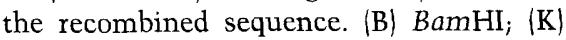
KpnI; (X) XbaI; (N) NotI; (H) HindIII; (Sl) SalI; (Sf) SfiI (B) Positive clones were verified by genomic Southern analysis. Analysis with different restriction enzyme digestions gives rise to labeled fragments that are consistent with a homologous recombination event. The structure of the $5^{\prime}$ recombined region was also confirmed by the loss of the $5^{\prime}$ SalI and XhoI sites that are contained within the targeting vector. Male and female $F_{1}$ mice were produced by mating C57B6/J females with chimeric males. Homozygous mice were produced from an intercross between $F_{1}$ mice. $(C)$ Kidneys of homozygous animals are smaller in size, fused longitudinally, and rotated $90^{\circ}$ ventrally. Arrowheads point to individual kidneys. The adrenal glands in mutants are smaller and are separated from the kidneys. Bar, $1.5 \mathrm{~mm}$ in both panels.

$B F-2$ is restricted to the stromal lineage of the developing kidney

To understand the potential role of BF-2 during kidney development, we examined its expression within the developing kidney by in situ hybridization and by assaying $\beta$-gal activity in BF-2 heterozygous animals. BF- 2 expression at E12.5 was found to be restricted to a population of cells that surround the condensations of the nephrogenic mesenchyme (Fig. 3E,F). BF-2 was not expressed in the condensates, the epithelium of the ureteric bud, or the future collecting system. At later developmental stages, the expression of BF-2 is detectable in the cortical stroma that surrounds differentiating nephrons and at lower levels in the medullary stroma surrounding the collecting system (Fig. 3H-J). Comparison of the in situ hybridization pattern of $\mathrm{BF}-2$ in wild-type embryos with the $\beta$-galactosidase staining pattern in $B F-2(+1-)$ and BF- $2(-1-1$ embryos demonstrated that the expression of the $\beta$-gal gene replacing the $B F$-2-coding sequence faithfully reflects the activity of the BF-2 promoter (Fig. 3 B,C,E,F; data not shown). The $\beta$-gal activity in heterozygous mice was then used to follow the fate of BF-2-positive cells in greater detail. $\beta$-Gal activity is not detected in the uninduced metanephric mesenchyme prior to the outgrowth of the ureteric bud. Shortly after the bud makes contact with the mesenchyme, the mesenchymal cells remain morphologically homogenous. However, two populations within the mesenchyme can be distinguished by their position relative to the ureteric bud (Fig. 3A). $\beta$-Gal staining reveals no staining in the mesenchyme that is adjacent to the ureteric bud epithelium. These BF-2-negative cells subsequently condense and differentiate into the tubular epithelium of the nephron. Pax-2 expression identifies these cells as the nephrogenic mesenchyme (Fig. 3D,G). BF-2 expression is confined to a ring of cells that surrounds the induced nephrogenic mesenchyme. BF-2 expression remains strong as these cells differentiate into the stroma of the kidney cortex (Fig. 3C,F). Expression of BF-2 persists but is weaker in the stroma of the medulla (Fig. $3 \mathrm{H}, \mathrm{I})$. Examination of lacZ-stained sections at E14.5 reveals a third population of cells derived from the metanephric mesenchyme. Some of the mesenchymal cells at the periphery of the developing kidney do not express BF-2 (Fig. 3J, arrowheads). These cells are smaller and rounder than the $\beta$-gal-positive stromal cells. They are also more abundant above the T-shaped ureteric branches in areas between condensed mesenchymal aggregates. The morphology and position of these cells suggest that they are mesenchymal stem cells (Saxen 1987; Ekblom 1992; Bard et al. 1994). These findings suggest that BF-2 expression is an early marker of the stromal cell lineage within the developing kidney.

Because BF-2 is normally expressed only within the stromal cell population, we examined the stroma in the $B F-2$ mutant to determine whether this lineage is absent or reduced. $\beta$-Gal activity in the $B F-2(-/-)$ mutant kidney remains restricted to the stromal lineage. In the E11.5 and E12.5 mutant kidney, lacZ-positive cells are found around mesenchymal condensations indicating that the stromal lineage is specified and formed normally (not shown). The number of stromal cells as defined morphologically and by lacZ staining appears to be similar between heterozygous and homozygous kidneys at early stages (Fig. 4; data not shown). Thus, it does not appear that a significant reduction in the number of stromal 

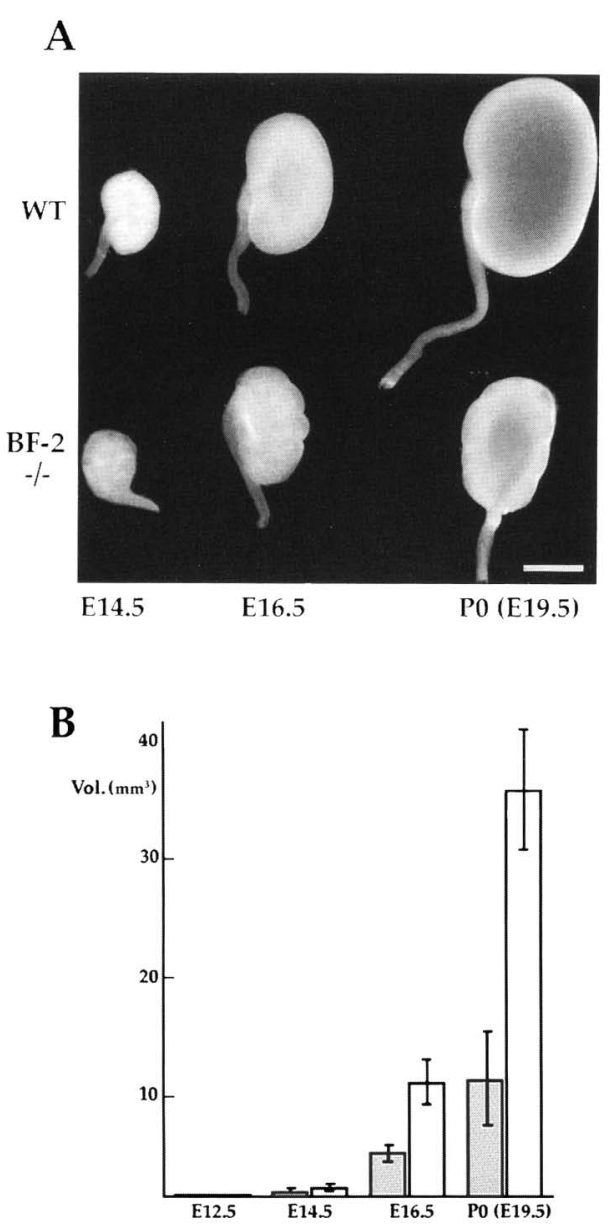

Figure 2. The growth rate of mutant kidneys is reduced in comparison to kidneys of wild-type embryos, during development. (A) Comparison between typical wild-type (upper row) and mutant kidneys (lower row) from the same litter during development. Within each litter there is variability in the size of the kidneys. However, mutant kidneys are clearly smaller then wild-type kidneys. $(B)$ The average volume of wild-type and homozygous kidneys was compared. Wild-type kidneys are larger by 2-fold at E14.5, 2.5-fold at E16.5, and 3.3-fold at P0. Bar in A, $1.5 \mathrm{~mm}$.

cells is the primary defect in the BF-2 mutant. Tenascin, a secreted glycoprotein, is a marker of early stromal cell differentiation (Aufderheide et al. 1987). To determine whether the specified stromal lineage differentiates and acquires stromal characteristics, we examined the expression of tenascin by immunohistochemistry. Tenascin immunoreactivity is found in the periphery of the kidney and surrounding mesenchymal condensates. The distribution and expression levels of tenascin in BF-2 $(-/-)$ kidneys are similar to that in wild-type kidneys (Fig 5A,B).

The number of nephrons is reduced in the BF-2 (-/-) kidney

One of the striking features of the BF-2 mutant kidneys by light microscopy is the dramatic reduction in the number of differentiated nephrons. At birth (P0), the number of nephrons was quantitated by counting the number of glomeruli per unit volume. Homozygous kidneys contain approximately one-quarter of the number of developing glomeruli per unit volume when compared with wild-type kidneys /see Materials and methods for details|. Because homozygous kidneys were less than one-third the size of wild-type kidneys, we estimate the total number of glomeruli in the homozygote to be $\sim 7 \%$ of the wild type. This reduction in the number of nephrons is associated with the abnormal presence of large amounts of condensed mesenchyme in the cortical and medullary regions of the kidney (Fig. 4I-K). To understand how these anomalies arose, we examined the early stages of kidney development.

Soon after making contact with the undifferentiated mesenchyme, the ureter bifurcates several times and the mesenchyme condenses around the tips of the ureter. No clear differences are apparent in the histology of the mutant and wild-type kidneys at E12.5. Mesenchymal condensations are found around the tips of the ureter in wild-type (Fig. 4A,B) and in mutant kidneys (Fig. 4C,D). Pax-2 (Fig. 6A,B) and Wnt-4 (Fig. 6E,F) expression marks these mesenchymal cells as the progenitors of the tubuIar epithelium of the nephron (Dressler et al. 1990; Stark et al. 1994). In wild-type animals, mesenchymal condensations undergo epithelial conversion and start to differentiate into tubular epithelium at E13.5 on the medullary side of the ureteric tip. BF-3 (also known as MFH-1) marks early tubular structures (Fig. 6C) (Miura et al. 1993). By E14.5, the outer half of the kidneys becomes subdivided into developmentally distinct regions, a cortical region that contains newly formed mesenchymal condensations, two to four cells thick, and a nephrogenic zone (Fig. 4E,F). The nephrogenic zone contains tubular structures at various stages of nephrogenic differentiation, including comma-shaped bodies, S-shaped bodies, and glomeruli (Figs. 4F and 6C). In contrast, E14.5 homozygous kidneys contain no distinct nephrogenic zone. Very few S-shaped and comma-shaped bodies are found in mutant kidneys. Instead, the outer half of the mutant kidney contains abnormally large mesenchymal condensations (Figs. 4G-H and $6 \mathrm{~B}, \mathrm{D}, \mathrm{F}$ ), which are up to 20 cells thick. These unusual mesenchymal condensates in the $B F-2(-/-)$ mutant kidney suggest that the differentiation of the mesenchyme into the tubular structures of the nephron is inhibited.

\section{Reduced growth and branching of the renal collecting system}

Another feature of the $B F-2$ mutant kidney is the reduced size of the collecting system (Fig. 4I,K). The collecting system is derived from the ureteric bud through a series of dichotomous branchings. Early branches eventually fuse together to form the renal pelvis while more distal branches become the collecting ducts that connect to the distal tubules of the nephron. The number of branches is clearly reduced by E14.5 in the $B F-2(-1-1$ mutant. In cross sections of developing kidney, we find 

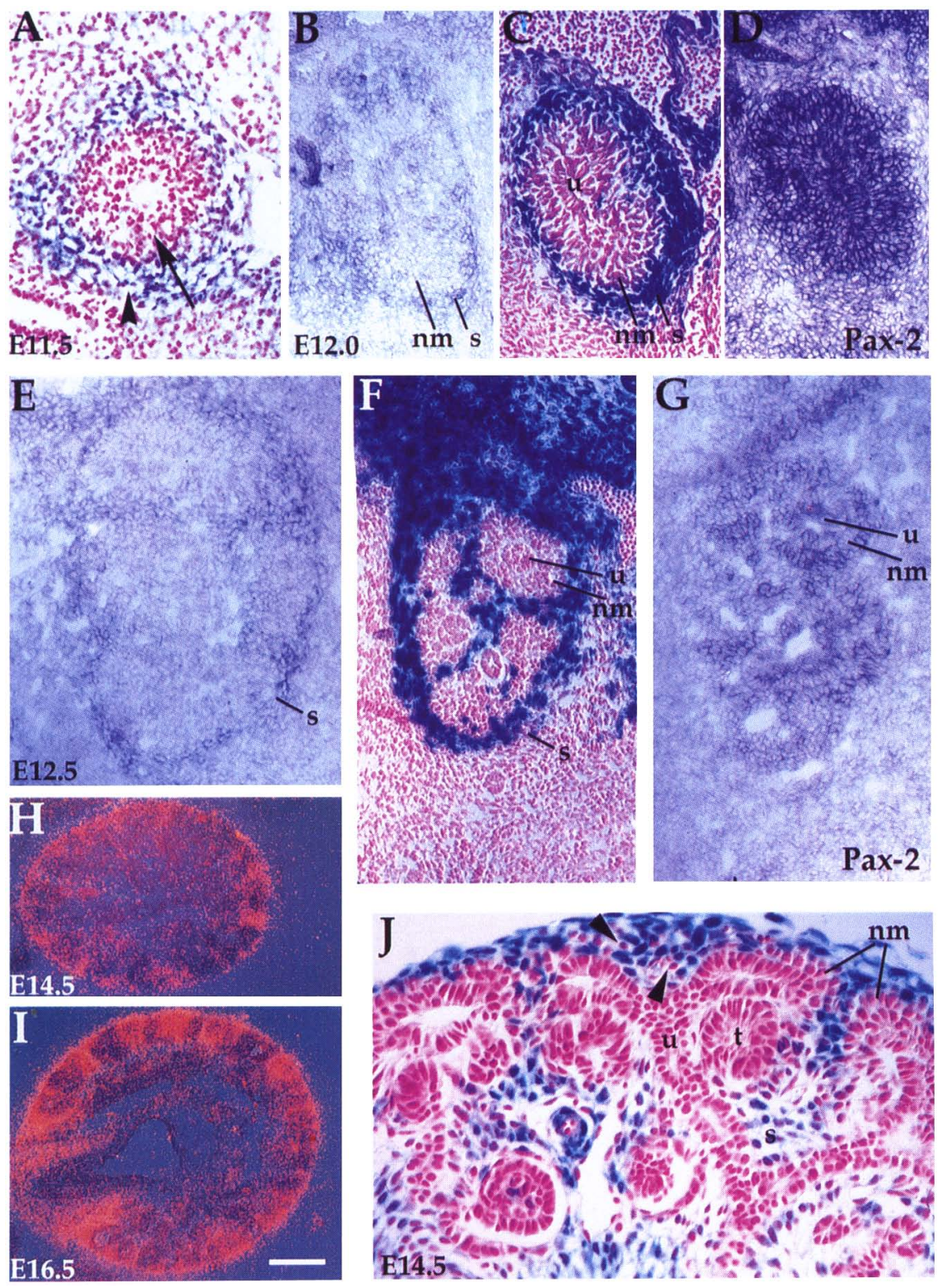

Figure 3. BF-2 expression in the developing kidney is restricted to cells of the stromal lineage. The expression of BF-2 was examined by in situ hybridization. $(B, E)$ digoxigenin probe; $(H, I)^{33} \mathrm{P}$-labeled probe; $(A, C, F) \beta$-gal reporter activity in $B F-2$ heterozygous mice. Pax- 2 expression in the nephrogenic mesenchyme is shown for comparison $(D, G)$. $(A) \beta$-Gal staining of E11.5 embryos reveals expression in a ring of mesenchyme (stromal mesenchyme, arrowhead) surrounding a BF-2-negative population (nephrogenic mesenchyme, arrow) around a central ureteric bud. $(B-D)$ Adjacent sections show expression of BF- 2 and lac $Z$ activity in a ring of cells surrounding the condensing nephrogenic mesenchyme. Pax- 2 is expressed adjacent to the BF- 2 and lacZ expression domains, in the condensed mesenchyme, and the ureteric bud epithelium. $(E-G)$ Comparable sections show expression of BF-2 and Pax-2 in adjacent nonoveralapping domains at E12.5. BF-2 is expressed in the periphery of the kidney and within the kidney rudiment surrounding mesenchymal condensations. BF-2 is also expressed in a subpopulation of intermediate and lateral mesoderm along the body axis. Pax- 2 is expressed in the adjacent condensed mesenchyme and the ureteric epithelium. $(H, I)$ At later developmental stages (E14.5 and E16.5, respectively| BF-2 is expressed at high levels in the periphery of the kidney and around the ureter in the pelvis. (J) At E14.5, a high level of $\beta$-gal staining is detected in the periphery of the kidney, surrounding mesenchymal condensations, and differentiating tubular structures (s). Note the presence of a second population of cells in the periphery interspersed among the $1 a c Z$ stained cells, which does not express BF-2 (arrowheads). Bar in $I, 25 \mu \mathrm{m}$ for $A-G ; 50$ $\mu \mathrm{m}$ for $J ; 200 \mu \mathrm{m}$ for $H$ and $I$. fewer branches of the ureter, which are surrounded by larger aggregates of mesenchyme (Fig. 4G). In situ hybridization with c-ret (Pachnis et al. 1993) and Wnt-4 (Stark et al. 1994) probes, markers of the ureter and the condensed mesenchyme, respectively, confirm these findings (Fig. 6E-H). To better visualize the branching pattern and the number of bifurcations in wild-type and mutant kidneys at E14.5, we stained whole-mount kidneys with dolichos biflorus agglutinin (DBA), a specific marker of the ureteric epithelium (Fig. 7). The collecting system of mutant and wild-type kidneys both branch dichotomously. However, abnormalities are observed in the mutant kidney in both the pattern of branching as well as the number of branches. The difference in the extent of branching was quantitated by counting the number of bifurcations. Homozygotes contain three to four bifurcations compared with seven to eight bifurca- tions along the longitudinal axis of the kidneys. Thus, the collecting system of $B F-2(-/-)$ embryos has undergone three to four fewer bifurcations in comparison to wild-type kidneys at E14.5. This is equivalent to a 8- to 16-fold reduction in the number of branches.

Differences between normal and BF-2 mutant kidneys are also observed in the expression pattern of the c-ret tyrosine kinase receptor. c-ret is initially expressed throughout the ureter and later becomes progressively restricted to the growing tips of the ureter (Pachnis et al. 1993). At E14.5 c-Ret is restricted to the tips of the ureter in the cortex of wild-type kidneys. In homozygous mutant mice, c-Ret expression is not restricted to the periphery of the kidney but is also found in the medullary region (Fig. 6G,H). We find ectopic expression of c-ret associated with ectopic mesenchymal condensates in the medulla. We also find that c-ret is not restricted to 
Hatini et al.
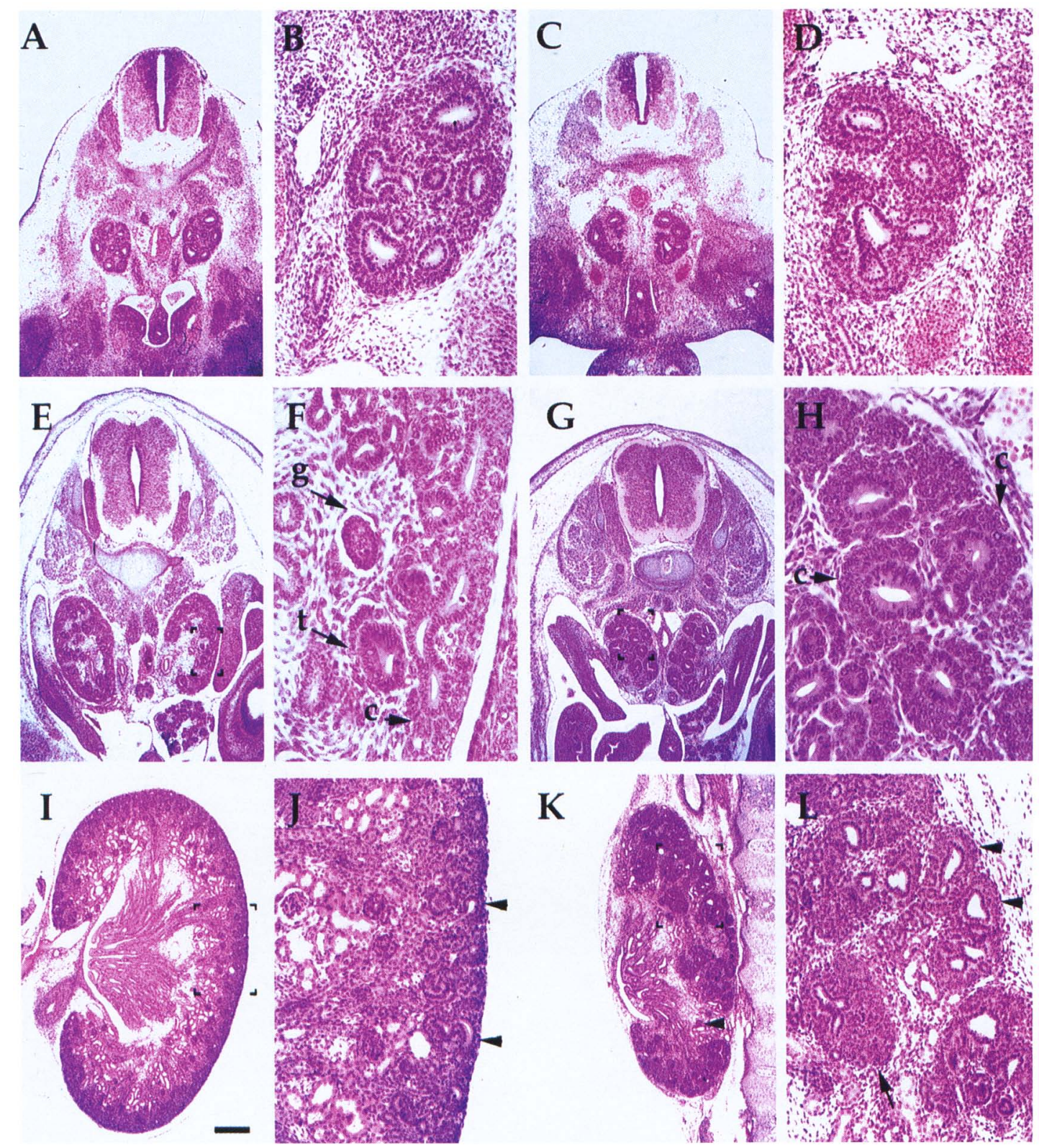

Figure 4. The growth of the collecting system and the differentiation of tubular structures are delayed in $B F-2$ null mice. Matching sections of wild-type $(A, B, E, F, I, J)$ and mutant $\langle C, D, G, H, K, L)$ kidneys at E12.5 $(A-D)$, E14.5 $(E-H)$ and P0 $(I-K)$. $(A, B)$ Wild-type kidneys contain mesenchymal condensations that surround the tips of the ureter; $(B)$ higher magnification of the right kidney. $(C-D)$ Homozygous kidneys also contain mesenchymal condensations; $(D)$ higher magnification of the right kidney. $(E, F)$ At E14.5, wild-type kidneys have a demarcated nephrogenic zone that contains tubular structures at various stages of nephrogenic differentiation; $(F)$ higher magnification of the region in brackets. Mesenchymal condensations (c), two to three cell layers thick, surround the tips of the ureter. Note the glomeruli $(\mathrm{g})$ and tubular epithelial structures $(\mathrm{t})$ in wild-type kidneys. $(G, H)$ At E14.5, homozygous kidneys are smaller and fused at the outer capsule. The ureter is located on the ventral side of the kidneys. Mutant kidneys contain numerous abnormally large mesenchymal aggregations, 5-20 cell layers thick, in the cortical and the medullary regions of the kidney. No distinct nephrogenic zone is found in mutant kidneys. $(I-L)$ Sections of P0 kidneys are parallel to the entry site of the ureter to the kidney; $(K)$ the homozygous kidneys are smaller in size and contain fewer nephrons per section; $(L)$ magnification of the bracketed region in $K$. Large condensations of mesenchyme are found in the cortex (arrowheads) and in the medullary region (arrow). The tips of homozygous collecting ducts are larger in comparison to wild type (arrowheads). The arrow in $K$ points to glomeruli in the mutant kidneys. Bar in I, $0.5 \mathrm{~mm}$ for $A, C, E, G, I, K ; 125 \mu \mathrm{m}$ for $B, D, I, L ; 60 \mu \mathrm{m}$ for $F$ and $H$.

the tips of the collecting system. Where the branches of the collecting system are cut longitudinally, expression of c-ret is observed to extend from the tip toward the medulla (arrowhead in Fig. 6H). 

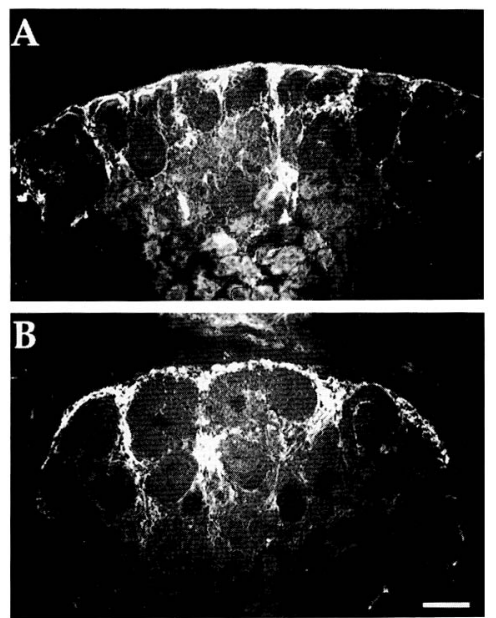

Figure 5. Tenascin, an early marker of stromal differentiation, is expressed in homozygous kidneys. Tenascin immunoreactivity in transverse sections through wild-type $(A)$ and homozygous $\mathrm{PO}(B)$ kidneys. $\langle A|$ Tenascin immunoreactivity is found in the periphery of the wild-type kidneys and surrounding pretubular mesenchymal aggregates. $(B)$ In mutant kidneys, the levels of expression are similar, and tenascin is also present in the periphery and surrounding mesenchymal condensates. Bar, 250 $\mu \mathrm{m}$.

\section{Discussion}

Kidney development has been studied extensively as a model of inductive interactions that regulate tissue morphogenesis. However, most studies to date only consider interactions between two components of the developing kidney, the ureteric bud and the metanephric mesenchyme. Although most of the cells of the metanephric mesenchyme will differentiate into the tubular epithelium of the nephron in response to signals from the ureter, a fraction gives rise to the interstitial cells of the kidney or the stroma. The fate and function of these mesenchymal cells has been largely ignored (Ekblom and Weller 1991), in part because of the dearth of specific molecular markers of this population of cells. Our results demonstrate that the expression of WH transcription factor BF-2 is restricted to the stromal cells of the developing kidney. Targeted disruption of the BF-2 gene leads to multiple defects in kidney development. Analyses of these mutant mice reveal the essential function of $\mathrm{BF}-2$ in the development of the kidney and provide new insight into the role of the stromal cell lineage in the differentiation of nephrogenic mesenchyme and the growth and branching of the ureteric epithelium.

\section{BF-2 and stromal cells are essential for kidney morphogenesis}

Stromal or interstitial cells can be clearly identified in the neonate kidney by their morphology and their location surrounding the epithelial structures of the nephrons and collecting system. We show that the expression of BF-2 is clearly restricted to stromal cells in the cortex and medulla of the P0 kidney. BF-2 is not detected in the collecting system nor in mature or differentiating nephrons. Earlier in development (E14.5), BF-2 expression is limited to the stroma in the medullary region of the kidney and to a subset of cells at the periphery of the kidney. The prevalent view is that the cells at the periphery are comprised of a bipotential stem cell population that is maintained during kidney development. The stem cell progenitor may adopt a nephrogenic fate through interactions with the branching ureteric bud or it may adopt a stromal fate (Saxen 1987; Bard et al. 1994). However, no lineage analysis has been performed to support this view. According to an alternative view, the primary inductive interactions with the ureteric bud segregate the metanephric mesenchyme into two different lineages at an early stage, a nephrogenic lineage and a stromal lineage, each with a distinct developmental fate (Sariola et al. 1988; Ekblom 1992). This issue has not been resolved satisfactorily. The expression of BF-2 clearly distinguishes two groups of cells in the periphery of the developing kidney, a BF-2-positive population and a second population of small, round cells that are interspersed between the BF-2-positive cells. On the basis of the morphology of the BF-2-positive cells and their subsequent colocalization with the stromal marker tenascin (Aufderheide et al. 1987), we believe that these cells are progenitors that are committed to the stromal cell lineage. The BF-2-negative cells are more abundant in areas between aggregates of condensing mesenchyme. These findings, together with the expression of Pax-2 in the BF-2-negative mesenchyme at E12, suggest that the BF2-negative cells are progenitors of the nephrogenic lineage. However, we cannot exclude the possibility that a subset of BF-2-negative cells retains the ability to differentiate into cells of the stromal lineage.

BF-2 is not detected in the metanephric mesenchyme prior to the outgrowth of the ureteric bud. Soon after the bud makes contact with the mesenchyme, BF- 2 becomes detectable in an outer ring of mesenchyme surrounding a zone of BF-2-negative mesenchyme immediately adjacent to the ureteric bud. The BF-2-negative mesenchyme initially expresses Pax- 2 and subsequently condenses and undergoes epithelial conversion. The BF-2-positive cells differentiate into the stroma. These results support the concept that two distinct cell lineages are induced within the metanephric mesechyme by signals from the ureteric bud, that is, the nephrogenic mesenchyme and the stromal mesenchyme. Our results cannot rule out the alternative possibilities that these two lineages preexist within the metanephric mesenchyme prior to the induction of BF-2 or that BF-2-expressing cells are recruited to the kidney upon induction of the mesenchyme. However, our studies show that $B F-2$ is the earliest genetic marker of the stromal cell lineage and that this lineage is already specified soon after the ureteric bud makes contact with the metanephric mesenchyme. Furthermore, by its absence in uninduced mesenchyme, nephrogenic stem cells, nephrogenic mesenchyme, and the ureteric epithelium, we infer that BF-2 does not function in the cells that differentiate into nephrons or the collecting system. The abnormal phenotype of the BF-2 


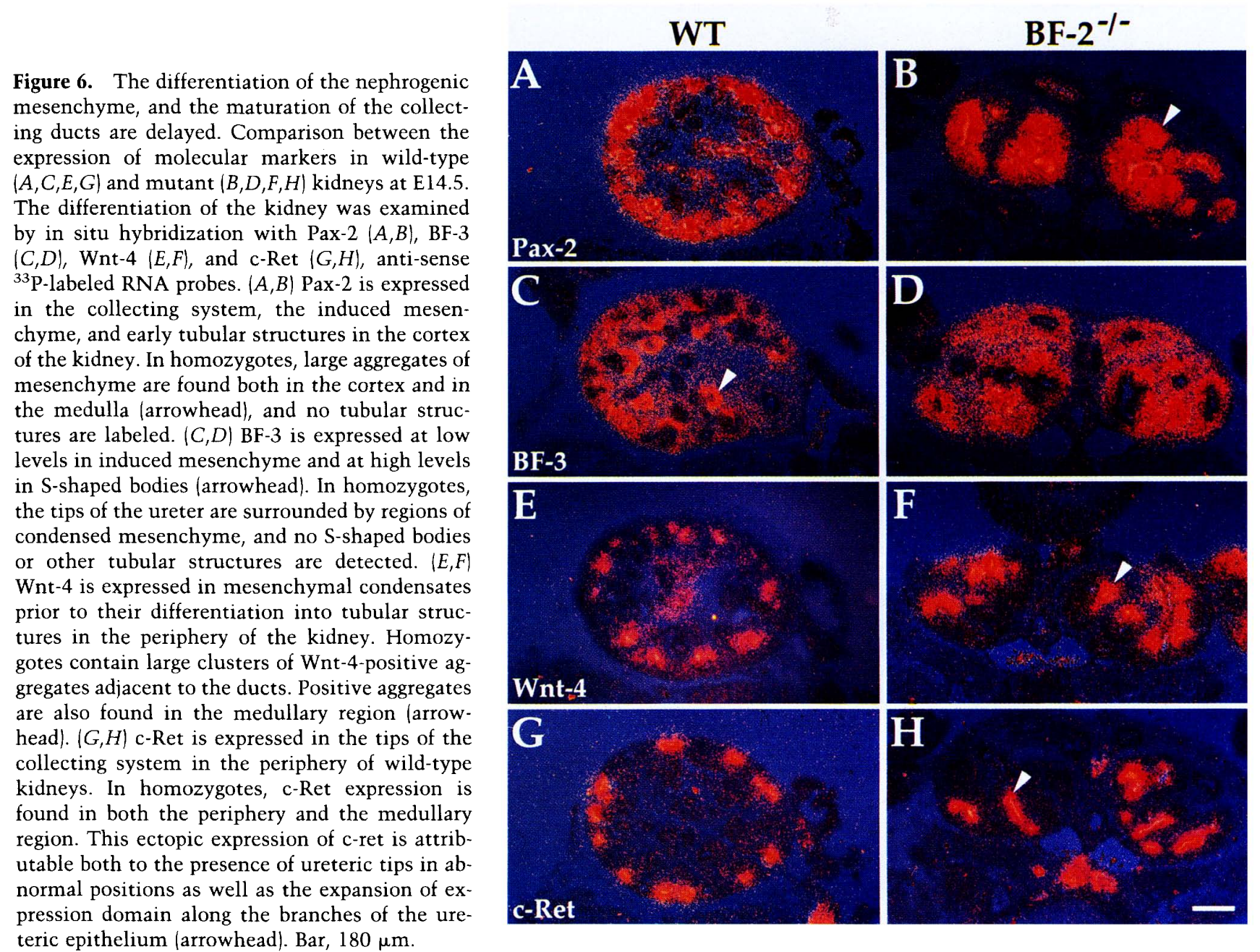

$|-/-|$ mutant kidney must therefore be attributed to the deficiency of an essential function of the stromal cell lineage that regulates the differentiation and proliferation of the nephrogenic and ureteric epithelia.

\section{BF-2 controls the rate of tubular differentiation}

The early stages of kidney development are not affected by the $B F-2$ mutation. The ureteric bud grows into the metanephric mesenchyme leading to the formation of mesenchymal aggregates and branching of the ureter. Thus, the inital inductive interactions between the ureter and the metanephric mesenchyme appear to occur normally in the BF-2 mutant. The induced mesenchyme surrounding the tips of the branching ureter aggregates to form the condensed mesenchyme and begins to differentiate into an epithelium. The effect of the BF-2 mutation is first apparent at the next stage of development, in which groups of cells separate from the pretubular aggregate to begin differentiating into tubular structures called comma-shaped and S-shaped bodies. This usually begins by E13.5. In the BF-2 $(-/-)$ mutant, no commashaped or S-shaped bodies are observed at E13.5 or E14.5. Instead of the formation of these tubular structures, we observe a progressive increase in the size of the con- densed mesenchymal or pretubular aggregates. The accumulation of this intermediate in the differentiation of nephrons suggests that the subsequent step in the differentiation pathway is affected in the $B F-2(-/-)$ mutant. The formation of a reduced number of comma-shaped and S-shaped bodies later in development indicates that tubular differentiation is not completely blocked. However, the rate of differentiation of the mesenchyme into a polarized tubular epithelium is severely reduced in the $B F-2(-/-)$ mutant kidney. We postulate that a normal function of the stroma is to produce factors that enhance this critical step in kidney morphogenesis.

The BF-2 mutation also results in a significant reduction in the rate of ureteric bud growth and branching. Although the branching of the collecting system remains dichotomous in the mutant kidney, the pattern of branching is abnormal. By E14.5, the number of ureteric branches is reduced 8- to 16-fold. Because the branching tips of the ureter progressively induce condensation of the nephrogenic mesenchyme, the reduction of branching morphogenesis in the BF-2 mutant leads to the formation of fewer than normal mesenchymal condensates, as well as a smaller collecting system. Furthermore, the abnormal pattern of branching leads to the presence of ureteric tips in both the periphery of the kidney and ec- 


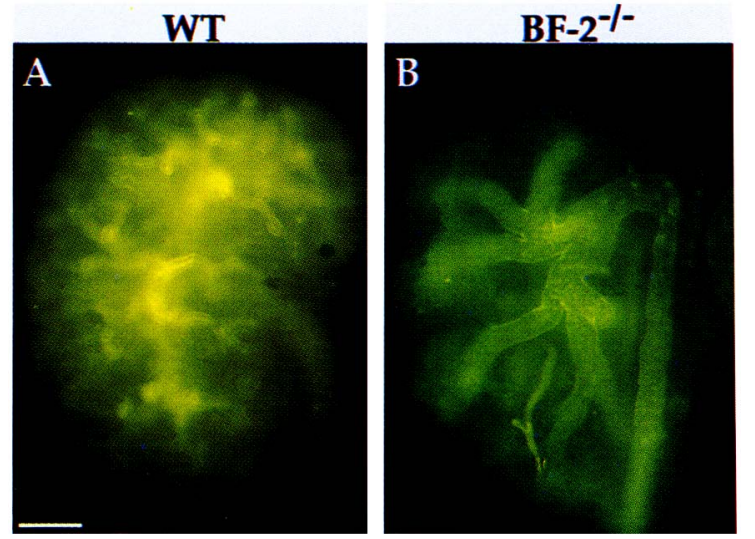

Figure 7. The branching of the ureter at E14.5 is reduced compared to wild type. The pattern of DBA staining, which labels the ureter epithelium, is compared between typical wild-type $(A)$ and mutant $(B)$ kidneys at E14.5. (B) A mutant kidney fused to its counterpart kidney. To estimate the difference in branching, kidneys from two litters were stained with DBA, and the number of branches were counted. On average, the wild-type ureter bifurcated six to eight times, and homozygous kidneys bifurcated three to four times. The branching pattern of mutant kidneys is dichotomous and is similar to wild type. Bar in A, 200 $\mu \mathrm{m}$.

topically in the medullary region, as confirmed by the expression pattern of c-ret (Fig. 7). In addition, c-ret expression is not restricted to the tips but is also found to extend along the branches of the developing collecting system. c-ret is initally expressed throughout the early ureteric bud. However, after the bud begins to branch, the expression of c-ret becomes restricted to the tips of the ureteric branches (Pachnis et al. 1993). Ectopic expression of c-ret along the ureteric branches in the $B F-2$ mutant suggests that differentiation of the ureteric epithelium may be blocked or delayed. Another feature of the BF-2 mutant is the short extrarenal ureters. Mutation of c-ret leads to failure of the ureter to branch and grow within the kidney but does not affect the elongation of the extrarenal ureter (Schuchardt et al. 1994). BF2-positive stromal cells surround the ureter as it enters the kidney. We suggest that stromal cells provide signals or factors that promote the growth of the ureter as well as the growth and branching of the developing collecting system.

In contrast to these severe defects in nephrogenesis and the formation of the collecting system, the stromal cell component itself is not altered morphologically. Because the early stages of kidney development are comparable between heterozygote and $B F-2(-/-)$ mutant, and because the pattern of $\beta$-gal expression at E12.5 in the mutant is unchanged from that in the heterozygote, we conclude that the stromal cell lineage is formed normally in the $B F-2(-/-)$ mutant. Using $\beta$-gal expression to mark the stroma, we find no significant reduction in the amount of stroma in the BF-2 mutant nor changes in its distribution within the kidney. The results show that the BF-2 mutation does not eliminate or significantly reduce the number of stromal cells. Therefore, we con- clude that the $B F-2$ mutation leads to a defect in the ability of the stromal cell lineage to produce factors that regulate kidney development.

\section{Molecular pathways controlled by BF-2}

The rapidly growing number of mouse mutations that affect the kidney, as well as several observations from in vitro studies of cultured kidney rudiments, have provided a clearer picture of the molecular and genetic pathways regulating kidney development. WT-1 and Pax-2 are both required for the outgrowth of the ureteric bud from the Wolffian duct. The Pax-2 heterozygote kidney phenotype also suggests defects in the proliferation and/ or differentiation of the metanephric mesenchyme (Torres et al. 1995). Kidneys grown in vitro in the presence of antisense Pax-2 oligonucleotides contain significantly reduced amounts of mesenchymal aggregates, indicating that Pax-2 acts to enhance aggregation following induction (Rothenpieler and Dressler 1993). In Wnt-4 null kidneys, the capacity of the mesenchyme to aggregate is reduced, and no tubular epithelium is formed, indicating that Wnt-4 may serve as an autocrine signal that is required for mesenchymal condensation and epithelialization (Stark et al. 1994). BF-2 functions at a similar or subsequent step in the differentiation of the mesenchyme. In BF-2 homozygotes, the induced mesenchyme condenses but differentiates poorly into tubular structures. The $B F-2(-/-)$ mutant phenotype is similar to that observed in vitro when kidney rudiments are incubated with antibodies to laminin A (Klein et al. 1988). Condensation of the mesenchyme occurs, but tubular differentiation is blocked. Because laminin A is believed to be important for the development of epithelial cell polarity, BF-2 may function to enhance the rate of this step in epithelial differentiation.

The abnormal development of the collecting system in the $B F-2(-/-)$ mutant may be directly attributable to deficiencies in the interaction of stroma with the ureteric epithelium. Alternatively, it may be a secondary consequence of the abnormal differentiation of the nephrogenic mesenchyme. Although our results do not clearly rule out this possibility, several observations suggest that secondary effects of abnormal nephrogenic differentiation do not entirely account for the reduction in growth and branching of the collecting system in the $B F-2(-/-)$ mutant. In the Wnt-4 $(-/-)$ mutant, a marked reduction in the formation of mesenchymal aggregates is observed to precede the development of abnormalities in the collecting system (Stark et al. 1994). Abnormalities in the collecting system are only apparent late on the fifteenth day of pregnancy. These findings demonstrate that development of the collecting system can proceed normally for some time despite the disruption of nephrogenic differentiation. In contrast, anomalies in the collecting system of the $B F-2(-/-)$ mutant are apparent at the same time that defects in nephrogenic differentiation are detectable (E13.0). Thus, we favor the possibility that signals from the stroma not only can act on the nephrogenic mesenchyme but also on the 
ureteric epithelium to promote its growth and branching. One such signal may be the as yet unidentified ligand for the c-ret receptor tyrosine kinase. Similarly, the reduced rate of nephrogenic tubular differentiation could also be indirectly mediated through signals from the ureteric epithelium rather than directly because of the absence of stromal factors. However, transfilter culture studies have shown that differentiation of the metanephric mesenchyme can proceed despite the removal of the ureter or other inducer after only $24 \mathrm{hr}$. At this stage, mesenchymal condensation is just beginning. In the absence of further signals from the ureter, tubular epithelial differentiation proceeds to form mature nephrons (Ekblom et al. 1981). Along with our present studies, these in vitro data suggest that stromal cells provide the factors required for the progression of the later stages of epithelial differentiation. In other organs that undergo branching morphogenesis such as the lung, salivary gland, and breast, the stromal mesenchyme is known to influence the growth and branching pattern of the adjacent epithelium (Bard 1990; Mizuno and Yasugi 1990). The stroma is a rich source of growth factors, and many of the corresponding receptors are found in the adjacent epithelium (Birchmeier and Birchmeier 1993). Thus, our studies best fit a model in which BF- 2 controls programs of gene expression within kidney stromal cells to produce factors that are essential for three processes: (1) the differentiation of condensed pretubular aggregates; (2) the growth and branching of the collecting system; and (3) the elongation of the ureter. The $B F-2(-/-)$ mutant mouse will faciliate the identification and characterization of these stromal factors.

\section{Materials and methods}

Construct design

The 129/Ola genomic DNA library (provided by A. Berns, The Netherlands Cancer Institute, Amsterdam) was screened with the XbaI-Xhol fragment of BF-2 cDNA (nucleotides 1-544). One genomic clone that contains a $14-\mathrm{Kb}$ fragment (clone 18) was characterized further and was used to construct the targeting vector. The authenticity of clone 18 was verified by comparing its restriction map to a genomic Southern blot of $\lambda 129$ mouse genomic DNA. A BamHI-H3 fragment derived from clone 18 , that contains $4.5 \mathrm{~kb}$ upstream of the transcription initiation site and $3 \mathrm{~kb}$ downstream was cloned into pGEM-4. The 5' BamHI site was changed into a SalI-XhoI site to permit linearization of the plasmid with a unique site prior to electroporation. The BF-2 gene encodes a 2446-nucleotide transcript that contains an open reading frame extending from nucleotide 366 to 1723 . To generate a $B F-2$ null mutation, a lac $Z$ cassette (M.E. Moynahan and M. Jasin, unpubl.) was inserted into the $X b a \mathrm{I}$ and NotI sites of $B F-2$ replacing a fragment spanning nucleotides $20-1633$ of the $B F-2$-coding region. A phosphoglycerokinase (PGK)-neo ${ }^{\mathrm{r}}$ cassette was then inserted into the NotI site in the same orientation as the BF-2 and the lacZ genes (Tybulewicz et al. 1991).

\section{Electroporation and selection of ES cells}

CJ7 ES cells (Swiatek and Gridley 1993) $\left(1.5 \times 10^{7} / 0.8 \mathrm{ml}\right)$ were electroporated with $25 \mu \mathrm{g}$ of SalI-digested targeting vector DNA using a Bio-Rad gene pulser at $(500 \mu \mathrm{F}, 250 \mathrm{~V})$. Treated cells were allowed to recover at room temperature for $15 \mathrm{~min}$ and then seeded on embryonic fibroblast feeder layers at a density of $5 \times 10^{5} / 6-\mathrm{cm}$ dish. ES cells were grown in a medium containing $10 \%$ fetal calf serum supplemented with leukemia inhibitory factor (LIF) at a concentration of $1000 \mathrm{U} / \mathrm{ml}$ (ESGRO). Medium was replaced $36 \mathrm{hr}$ after electroporation with selection medium containing $250 \mu \mathrm{g}$ of active G-418 (GIBCO). Cells were maintained under selection for 7-8 days, with selection medium being replaced every other day.

\section{Screening of G-418-resistant colonies}

After 7-8 days of selection, colonies were picked and trypsinized. Two-thirds of each clone was seeded in a 96-well plate, amplified, and analyzed by PCR for correctly targeted clones. The remaining one-third was transferred to a duplicate 96-well plate and grown under G-418 selection until the PCR result was obtained. Resistant clones were analyzed by PCR using the $5^{\prime}$ PGK primer (LeMouellic et al. 1990), 5'-AGTATTGTTTTGCCAAGTTCTAAT-3', and a $3^{\prime}$ BF-2 primer, 5'AAAATCGAATACTCCTGTTA-3'. The approximate positions of these primers are indicated in Figure 1A. The amplified DNA product is $\sim 1 \mathrm{~kb}$ in size. The PCR run includes 40 cycles of $15 \mathrm{sec}$ at $94^{\circ} \mathrm{C}, 30 \mathrm{sec}$ at $55^{\circ} \mathrm{C}$, and $1 \mathrm{~min}$ at $72^{\circ} \mathrm{C}$. Positive clones were amplified for injection into blastocysts, genomic Southern analysis, and karyotype analysis. Four of the PCRpositive clones integrated the targeting vector by homologous recombination as confirmed by genomic Southern blot analysis (Fig. 1B). These clones were injected into blastocysts from C57BL6/J females. One clone (clone 365) transmitted the BF-2 deletion through the germ line. Nine founder males were bred to $\mathrm{C} 57 \mathrm{BL} 6 / \mathrm{J}$ to generate a pool of $B F-2$ heterozygous mice that were used in subsequent experiments.

\section{Southern blot analysis of ES cell line and mice}

Genomic DNA was obtained from ES cells, mouse tail tips, and embryonic sacs as described previously (Hogan et al. 1986; Bonnerot and Nicolas 1993). Ten micrograms of ES cell DNA or tail tip DNA was purified and digested with restriction endonucleases. Digested DNA was transferred to a Zeta-probe membrane and hybridized with a random-primed probe, 3Pl (Hatini et al. 1994), overnight at $65^{\circ} \mathrm{C}$. Membranes were washed according to the manufacturer's protocol (Bio-Rad).

\section{Histology}

Dissected embryos were genotyped by genomic Southern analysis and fixed in Bouin's solution. Fixation times varied as follows: overnight for P0, $6 \mathrm{hr}$ for E14.5, and $4 \mathrm{hr}$ for E12.5. Embryos were cleared and embedded in paraffin wax (Paraplast). Blocks were sectioned at $8 \mu \mathrm{m}$ and stained with Gill's hematoxylin and eosin stain. For whole-mount $\beta$-gal staining, intact kidneys were fixed in $4 \%$ paraformaldehyde in PBS, washed three times in PBS, and stained at $30^{\circ} \mathrm{C}$ until a desired staining intensity was obtained. For $\beta$-gal staining of frozen sections, kidneys were fixed with $4 \%$ paraformaldehyde for $10 \mathrm{~min}$, washed three times with PBS, immersed in $30 \%$ sucrose in PBS overnight, and embedded in OCT compound (Miles). Frozen sections $(8 \mu \mathrm{m})$ were cut and dried for $1 \mathrm{hr}$ at room temperature. Sections were washed in PBS, stained overnight with $\beta$-gal staining solution at $30^{\circ} \mathrm{C}$, and counterstained with nuclear fast red stain.

\section{In situ hybridization}

Embryos were dissected in ice-cold PBS and fixed for $4 \mathrm{hr}$ with $4 \%$ paraformaldehyde. Embryos were cleared in Histoclear and 
embedded in paraffin wax (Paraplast, Fisher). Eight-micron sections were cut and processed for hybridization (Wilkinson 1992). Sections were dewaxed in histoclear and rehydrated, then heat treated with $2 \times \mathrm{SSC}$ for $30 \mathrm{~min}$ at $70^{\circ} \mathrm{C}$. Sections were treated with $20 \mu \mathrm{g} / \mathrm{ml}$ of proteinase $\mathrm{K}$ for $7.5 \mathrm{~min}$ to permeabilize the tissue and then postfixed for $20 \mathrm{~min}$ with $4 \%$ paraformaldehyde. Slides were acetylated for $10 \mathrm{~min}$ with $0.1 \mathrm{M}$ triethanol amine and acetic anhydride, dehydrated, and dried for several hours. Hybridization mixture $(1.5 \mathrm{ng} / \mu$ l of antisense RNA, $1 \mu \mathrm{g} / \mu \mathrm{l}$ of tRNA, $50 \%$ formamide, $10 \%$ dextran sulfate, $0.3 \mathrm{M}$ $\mathrm{NaCl}, 0.01 \mathrm{M}$ Tris- $\mathrm{HCl}, 0.1 \mathrm{M} \mathrm{NaPO}_{4}$ at $\mathrm{pH} 6.8,5 \mathrm{~mm}$ EDTA, $0.02 \%$ Ficoll-400, $0.02 \%$ polyvinilpyrolidone, $0.02 \%$ BSA fraction V) was then applied on top of the section, overlaid with parafilm, and incubated overnight at $58^{\circ} \mathrm{C}$ in a moisture chamber containing $50 \%$ formamide in $\mathrm{H}_{2} \mathrm{O}$. The next day, sections were washed for $1 \mathrm{hr}$ with $4 \times$ SSC and for $40 \mathrm{~min}$ with $2 \times$ SSC, $50 \%$ formamide, at $65^{\circ} \mathrm{C}$. Sections were then treated with 20 $\mu \mathrm{g} / \mathrm{ml}$ of RNase for $30 \mathrm{~min}$ at $37^{\circ} \mathrm{C}$, followed by a second high stringency wash with $2 \times$ SCC, $50 \%$ formamide, for $30 \mathrm{~min}$ at $50^{\circ} \mathrm{C}$. Sections were dehydrated and dipped into photographic emulsion. Slides hybridized with BF-2, c-Ret and Wnt-4 were exposed to emulsion for 10 days, and sections hybridized with BF-3 and Pax-2 were exposed for 6 days. Developed slides were lightly counterstained with Gill's hematoxylin and eosin stain.

$B F-2, B F-3, P a x-2, c-r e t$, and Wnt-4 cDNA template were used to generate ${ }^{33} \mathrm{P}$-labeled antisense RNA probes. BF-2 3Pl cDNA template was linearized with EcoRI, and a $0.6-\mathrm{kB}$ antisense RNA was synthesized using T7 polymerase as described previously (Hatini et al. 1994). BF-3 clone 7 was isolated from a AShlox E10 mouse cDNA library (Novagene), and subcloned into pBluescript KS. This clone was sequenced on both strands and contains a full-length cDNA of BF-3 with a complete open reading frame (S. Xuan and E. Lai, unpubl.). An identical clone was independently isolated and was named MFH-1 (Miura et al. 1993). BF-3 cDNA template was linearized with HindIII, and a $2.5-\mathrm{kb}$ antisense RNA was synthesized using $\mathrm{T} 7$ promoter. $P a x-2$ cDNA template was linearized with $B a m H I$, and a 0.6-kb antisense RNA was transcribed using $\mathrm{T} 7$ polymerase (Dressler et al. 1990). mcRet 7 cDNA template was linearized with NotI, and a $2.8-\mathrm{kb}$ antisense RNA was transcribed using $\mathrm{T} 7$ polymerase (Pachnis et al. 1993). Wnt-4 cDNA template was linearized with $B a m H I$, and a $0.43-\mathrm{kb}$ antisense RNA was synthesized using T7 polymerase (Stark et al. 1994). Probes were synthesized in a transcription mixture containing $100 \mu \mathrm{Ci}$ of $\left[{ }^{33} \mathrm{P}\right] \mathrm{UTP}$ with no added cold UTP in a final volume of $10 \mu \mathrm{l}$. RNA probes were then hydrolyzed to an average length of $200 \mathrm{bp}$.

For nonradioactive in situ hybridization, using digoxigeninlabeled antisense riboprobe (Wilkinson 1992), embryos were fixed for $1 \mathrm{hr}$ in $4 \%$ paraformaldehyde in PBS and then immersed in $30 \%$ sucrose in PBS for several hours. Eight-micron sections were hybridized at $58^{\circ} \mathrm{C}$. Following hybridization, the first high stringency wash was at $60^{\circ} \mathrm{C}$, for $40 \mathrm{~min}$ in $1 \times$ SSC and $50 \%$ formamide. The second high stringency wash was at $60^{\circ} \mathrm{C}$ for $40 \mathrm{~min}$ in $1 \times \mathrm{SSC}$ and $50 \%$ formamide. For immunohistochemical detection of digoxigenin, sections were initially incubated in buffer A $(100 \mathrm{mM}$ Tris- $\mathrm{HCl}$ at $\mathrm{pH} 7.5,150 \mathrm{~mm}$ $\mathrm{NaCl}$, and then blocked at room temperature for $1 \mathrm{hr}$ in mouse E13.5 embryonic powder in buffer A containing $0.5 \%$ Triton $\mathrm{X}-100$. Sections were then incubated with alkaline phosphataseconjugated sheep polyclonal antidigoxigenin antibody (Boehringer Mannheim), diluted 1:3000 in buffer A containing 1\% NSS, $0.5 \%$ Triton $\mathrm{X}-100$, at $4^{\circ} \mathrm{C}$ overnight. The next day sections were washed three times for $10 \mathrm{~min}$ each with buffer A, and then washed in buffer $\mathrm{B}(100 \mathrm{mM}$ Tris- $\mathrm{HCl}$ at $\mathrm{pH} 9.5,100$ $\mathrm{mM} \mathrm{NaCl}, 50 \mathrm{~mm} \mathrm{MgCl}_{2}$ ) for $10 \mathrm{~min}$. Alkaline phosphatase detection was developed in the presence of nitroblue tetrazoli- um, BCIP, and levamisol in buffer B at room temperature in the dark. Sections were dehydrated and coverslipped with Permount (Fisher Scientific).

\section{Immunohistochemistry}

For whole-mount staining of E14.5 kidneys with fluoresceinDBA, kidneys were dissected and fixed for $10 \mathrm{~min}$ in $2 \%$ paraformaldehyde. Kidneys were then blocked with 3\% BSA in PBS with $0.05 \%$ Triton X-100 (PBS-TX) for $1 \mathrm{hr}$ at $37^{\circ} \mathrm{C}$. Kidneys were then incubated for $1 \mathrm{hr}$ at $37^{\circ} \mathrm{C}$ with DBA /Vector Labs) diluted 1:40 in PBS-TX with 3\% BSA. Tenascin staining was performed with mAb MTn-12 (Sigma). Staining was visualized using a Zeiss fluorescence microscope equipped with a fluorescein filter.

\section{Quantitation of kidney volume and glomeruli}

To measure the volume of wild-type and mutant kidneys, each kidney was measured with a micrometric grid in three axes, longitudinal, dorsoventral, and mediolateral. The average axis length was used to calculate the volume of each kidney. Several kidneys from each stage were measured. We found the following: Wild-type E14.5 kidneys $\left(n=6,0.8 \mathrm{~mm}^{3}\right.$, S.D. $\left.=0.27\right)$ were 2.1 -fold the volume of mutant kidneys $\left(n=6,0.37 \mathrm{~mm}^{3}\right.$, S.D. $=0.13)$. Wild-type E16.5 kidneys $\left(n=5,10.6 \mathrm{~mm}^{3}\right.$, S.D. $\left.=2.0\right)$ were 2.6 the volume of mutants $\left(n=5,4.1 \mathrm{~mm}^{3}\right.$, S.D. $\left.=0.7\right)$; and wild-type P0 kidneys $\left(n=4,36.2 \mathrm{~mm}^{3}\right.$, S.D. $\left.=5.4\right)$ were 3.3 -fold the volume of mutants $\left(n=8,10.9 \mathrm{~mm}^{3}\right.$, S.D. $\left.=4.3\right)$. These numbers were used to create the bar graph in Figure 2 . The length of the mutant ureter $(n=3,2.37 \mathrm{~mm}$, s.D. $=0.29)$ is $\sim 60 \%$ the length of the wild-type ureter $(n=3,3.84 \mathrm{~mm}$, S.D. $=0.29)$.

Glomeruli were counted in wild-type $(n=5)$ and mutant kidneys $(n=5)$. The number of glomeruli was determined in multiple mid-sagittal sections encompassing the whole cross section of the kidney, including both the cortical and medullary regions. We found an average of 24.7 glomeruli (S.D. $=1.2$ ) in wild-type kidneys, compared to 4.4 glomeruli (S.D. $=3.3$ ) in $\mathrm{mu}$ tants, per $10 \mathrm{~mm}^{2}$. Then taking into account the 3.3 -fold greater volume of the wild-type kidney, we calculate that mutant kidneys contain $7.3 \%$ (S.D. $=5.3 \%$ ) of the number of glomeruli in wild-type kidneys.

\section{Acknowledgments}

We thank G. Balas and A. Kremer for excellent technical support, F. Costantini, P. Gruss, A. McMahon for probes, T. Gridley for CJ7 ES cells, and M. Jasin for targeting vectors. We also thank the members of the Transgenic Facility and the Molecular Cytology Facility for their help. This work was supported by grants from the National Institutes of Health to E.L. (RO1 EY11124) and to Memorial Sloan-Kettering Cancer Center (Cancer Center Support grant).

The publication costs of this article were defrayed in part by payment of page charges. This article must therefore be hereby marked "advertisement" in accordance with 18 USC section 1734 solely to indicate this fact.

\section{References}

Ang, S.L. and J. Rossant. 1994. HNF-3 $\beta$ is essential for node and notochord formation in mouse development. Cell 78: 561574.

Aufderheide, E., E.R. Chiquet, and P. Ekblom. 1987. Epithelialmesenchymal interactions in the developing kidney lead to expression of tenascin in the mesenchyme. J. Cell Biol. 105: 599-608.

Bard, J. 1990. Morphogenesis: The cellular and molecular pro- 
cesses of developmental anatomy. Cambridge University Press, Cambridge, MA.

Bard, J.B., J.E. McConnell, and J.A. Davies. 1994. Towards a genetic basis for kidney development. Mech. Dev. 48: 3-11.

Birchmeier, C. and W. Birchmeier. 1993. Molecular aspects of mesenchymal-epithelial interactions. Annu. Rev. Cell Biol. 9: $511-540$.

Bonnerot, C. and J. Nicolas. 1993. Application of LacZ fusions to postimplantation development. In Guide to techniques in mouse development. (ed. P. Wasserman and M. DePamphilis), pp. 451-469. Academic Press, San Diego, CA.

Cunha, G.R. 1976. Epithelial-stromal interactions in the development of the urogenital tract. Int. Rev. Cytol. 47: 137-194.

Dressler, G.R., U. Deutch, K. Chowdhury, H.O. Nornes, and P. Gruss. 1990. Pax-2, a new paired-box gene and its expression in the developing excretory system. Development 109: 785795.

Dudley, A.T., K.M. Lyons, and E.J. Robertson. 1995. A requirement for bone morphogenetic protein-7 during development of the mammalian kidney and eye. Genes \& Dev. 9: 27952807.

Ekblom, P. 1992. Renal development in the kidney: Physiology and pathophysiology. Raven Press Ltd., New York, NY.

Ekblom, P. and A. Weller. 1991. Ontogeny of tubulointerstitial cells. Kideny Int. 39: 394-400.

Ekblom, P., A. Miettinen, I. Virtanen, T. Walstrom, A. Danway and L. Saxen. 1981. In vitro segregation of the metanephric nephron. Dev. Biol. 84: 88-95.

Gossens, C.L. and B.R. Unsworth. 1972. Evidence for a two-step mechanism operating during in vitro mouse kidney tubulogenesis. I. Embryol. Exp. Morphol. 28: 615-631.

Grobstein, C. 1955. Inductive interaction in the development of the mouse metanephros. J. Exp. Zool. 130: 319-340.

- 1956. Trans-filter induction of tubules in the mouse metanephrogenic mesenchyme. Exp. Cell Res. 10: 424-440.

Haffen, K., M. Kedinger, and P. Simonassmann. 1987. Mesenchyme-dependent differentiation of epithelial progenitor cells in the gut. I. Pediatr. Gastroenterol. 6: 15-23.

Hatini, V., W. Tao, and E. Lai. 1994. Expression of winged helix genes, BF-1 and BF-2, define adjacent domains within the developing forebrain and retina. I. Neurobiol. 25: 12931309.

Hilfer, S.R., R.M. Rayner, and J.W. Brown. 1985. Mesenchymal control of branching pattern in the fetal mouse lung. Tissue Cell 17: 523-538.

Hogan, B., E. Lacy, and F. Costantini. 1986. Manipulating the mouse embryo. Cold Spring Harbor Laboratory, Cold Spring Harbor, NY.

Klein, G., M. Langegger, R. Timpl, and P. Ekblom. 1988. Role of laminin A chain in the development of epithelial cell polarity. Cell 55: 331-34l.

Kreidberg, J.A., H. Sariola, J.M. Loring, M. Maeda, J. Pelletier, D. Housman, and R. Jaenisch. 1993. WT-1 is required for early kidney development. Cell 74: 679-691.

Lai, E., V.R. Prezioso, W. Tao, W.S. Chen, and J.E. Darnell Jr. 1991. Hepatocyte nuclear factor $3 \alpha$ belongs to a gene family in mammals that is homologous to the Drosophila homeotic gene fork head. Genes \& Dev. 5: 416-427.

Lai, E., K.L. Clark, S.K. Burley, and J.E. Darnell. 1993. Hepatocyte factor $3 /$ fork head or "winged helix" proteins: A family of transcription factors of diverse biologic function. Proc. Natl. Acad. Sci. 90: 10421-10423.

LeMouellic, H., H. Condamine, and P. Brulet. 1990. Targeted replacement of the homeobox gene Hox 3.1 by the E. coli LacZ in mouse chimeric embryos. Proc. Natl. Acad. Sci. 87: 4712-4716.
Luo, G., C. Hofmann, A.L.J.J. Bronckers, M. Sohocki, A. Bradley, and G. Karsenty. 1995. BMP-7 is an inducer of morphogenesis, and is also required for eye development and skeletal patterning. Genes \& Dev. 9: 2808-2820.

Miura, N., A. Wanaka, M. Tohyama, and K. Tanaka. 1993. MFH-1, a new member of the fork head domain family, is expressed in developing mesenchyme. FEBS Lett. 326: 171176.

Mizuno, T. and S. Yasugi. 1990. Susceptibility of epithelia to directive influence of mesenchyme during organogenesis: Uncoupling of morphogenesis and cytodifferentiation. Cell Differ. Dev. 31: 151-159.

Nehls, M., D. Pfeifer, M. Schorpp, H. Hedrich, and T. Boehm. 1994. New member of the winged-helix protein family disrupted in mouse and rat nude mutations. Nature 372: 103107.

Pachnis, V., B. Mankoo, and F. Costantini. 1993. Expression of the c-ret proto-oncogene during mouse embryogenesis. Development 119: 1005-1017.

Rothenpieler, U.W. and G.R. Dressler. 1993. Pax-2 is required for mesenchyme-to-epithelium conversion during kidney development. Development 119: 711-720.

Sariola, H., E. Aufderheide, H. Bernhard, F.S. Henke, W. Dippold, and P. Ekblom. 1988. Antibodies to cell surface ganglioside GD3 perturb inductive epithelial-mesenchymal interactions. Cell 54: 235-245.

Saxen, L. 1987. Organogenesis of the kidney. Cambridge University Press, Cambridge, MA.

Schuchardt, A., V. D'Agati, B.L. Larsson, F. Costantini, and V. Pachnis. 1994. Defects in the kidney and enteric nervous system of mice lacking the tyrosine kinase receptor Ret. Nature 367: 380-383.

Stark, K., S. Vainio, G. Vassileva, and A.P. McMahon. 1994. Epithelial transformation of metanephric mesenchyme in the developing kidney regulated by Wnt-4. Nature 372: 679683.

Swiatek, P.J. and T. Gridley. 1993. Perinatal lethality and defects in hindbrain development in mice homozygous for a targeted mutation of the zinc finger gene Krox-20. Genes \& Dev. 7: 2071-2084.

Torres, M., E. Gomez-Pardo, G.R. Dressler, and P. Gruss. 1995. Pax-2 controls multiple steps of urogenital development. Development 121: 4057-4065.

Tybulewicz, V.L.J., C.E. Crawford, P.K. Jackson, R.T. Bronson, and R.C. Mulligan. 1991. Neonatal lethality and lymphopenia in mice with a homozygous disruption of the c-abl protooncogene. Cell 65: 1153-1163.

Weigel, D., G. Jürgens, F. Kuttner, E. Seifert, and H. Jäckle. 1989. The homeotic gene fork head encodes a nuclear protein and is expressed in the terminal regions of the Drosophila embryo. Cell 57: 645-658.

Weinstein, D.C., A. Ruiz i Altaba, W.S. Chen, P. Hoodless, V.R. Prezioso, T.M. Jessell, and J.E. Darnell. 1994. The wingedhelix transcription factor HNF-3 $\beta$ is required for notochord development in the mouse embryo. Cell 78: 575-588.

Wessells, N.K. 1970. Mammalian lung development: Interactions in formulation and morphogenesis of tracheal buds. $J$. Exp. Zool. 175: 455-466.

Wilkinson, D.G. 1992. In situ hybridization, a practical approach. IRL Press, Oxford, UK.

Xuan, S., C.A. Baptista, G. Balas, W. Tao, V.C. Soares, and E. Lai. 1995. Winged helix transcription factor BF-1 is essential for the development of the cerebral hemispheres. Neuron 14: 1141-1152. 


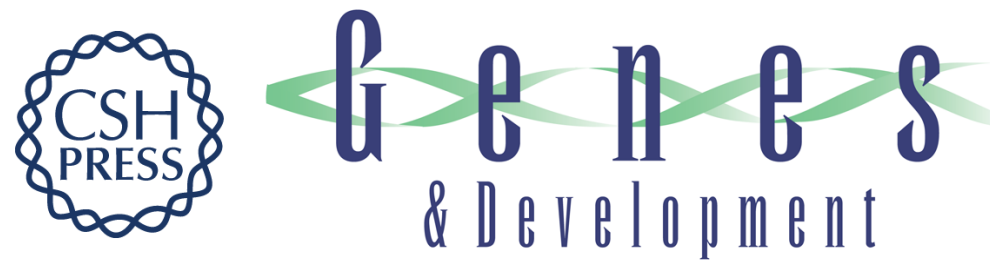

\section{Essential role of stromal mesenchyme in kidney morphogenesis revealed by targeted disruption of Winged Helix transcription factor BF-2.}

V Hatini, S O Huh, D Herzlinger, et al.

Genes Dev. 1996, 10:

Access the most recent version at doi:10.1101/gad.10.12.1467

References This article cites 36 articles, 10 of which can be accessed free at: http://genesdev.cshlp.org/content/10/12/1467.full.html\#ref-list-1

License

Email Alerting Service

Receive free email alerts when new articles cite this article - sign up in the box at the top right corner of the article or click here.

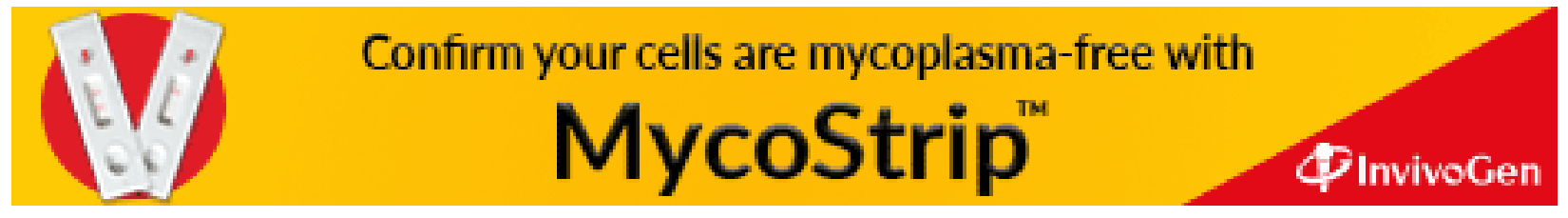

